\title{
Penerapan Vertical Harvesting dan Rainwater Harvesting pada Apartemen untuk Mengurangi Fenomena Urban Heat Island di Jakarta
}

\author{
Farizan Putri Andini dan Muhammad Faqih \\ Departemen Arsitektur, Fakultas Arsitektur, Desain dan Perencanaan, Institut Teknologi Sepuluh Nopember (ITS) \\ e-mail: faqih@arch.its.ac.id
}

\begin{abstract}
Abstrak-Kota Jakarta merupakan kota terbesar di Indonesia dengan luas sekitar $661,52 \mathrm{~km}^{2}$. Sehingga sampai saat ini, Jakarta sangat marak akan urbanisasi yang menyebabkan masalah kepadatan penduduk. Dengan letaknya yang berada di daerah tropis serta memiliki angka kepadatan penduduk yang tinggi terciptalah masalah yang serius yaitu urban heat island (UHI). Salah satu penyebab terjadinya urban heat island ini adalah berkurangnya lahan hijau yang dijadikan bangunan yang dapat meningkatkan temperatur perkotaan karena tuntutan bertambanya penduduk di Jakarta, khususnya kawasan Kelapa Gading. Sehingga, pada artikel ini akan dibahas mengenai perancangan apartemen dengan pendekatan biophilic yang ramah lingkungan agar tercipta keterkaitan antara alam, manusia dan bangunan itu sendiri, serta dapat memberikan jawaban dalam mengurangi tingginya temperatur (fenomena urban heat island) pada pusat perkantoran dan daerah perumahan di kota Jakarta. Selain dapat mengurangi fenomena urban heat island, sebagaimana konsep dari perancangan apartemen tersebut yaitu sebagai hutan Jakarta, rancangan juga berguna untuk mengurangi beban kebutuhan air, menghasilkan pangan, sebagai tempat tinggal untuk berlindung (papan) dan sumber penghidupan lainnya bagi penghuni. Sehingga, untuk memenuhi konsep tersebut, apartemen dengan ketinggian $\mathbf{\pm 2 0}$ lantai ini dilengkapi dengan berbagai fasilitas yang meningkatkan kualitas lingkungan. Beberapa diantaranya seperti, balkon yang tersebar di fasad bangunan sebagai media penanaman pohonpohon penghasil $\mathrm{O}_{2}$, organic market untuk distribusi sumber pangan, ruang terbuka hijau yang cukup luas untuk menyerap dan menampung air hujan, dsb.
\end{abstract}

Kata Kunci-Apartemen, Biophilic, Hutan, Jakarta, Kepadatan Penduduk, Urban Heat Island.

\section{PENDAHULUAN}

$\mathrm{S}$ EJAK muncul revolusi industri abad 18 hingga kehidupan modern saat ini, penggunaan bahan bakar minyak bagi keperluan kehidupan manusia melonjak demikian cepatnya. Bahan bakar minyak, batu bara dan gas yang digunakan manusia dan mengemisikan $\mathrm{CO}_{2}$ ke atmosfir dalam jumlah besar dan dalam satuan waktu tertentu mengakibatkan penebalan selimut bumi dan semakin banyak pula panas yang terperangkap didalam bumi. Situasi ini lah yang memunculkan fenomena pemanasan bumi, atau global warming. Bukan hanya itu, Woodwell, ahli biologi dan lingkungan, berpendapat bahwa berkurangnya vegetasi per satuan luas tertentu akibat pembangunan kota baru atau pemekaran kota mengurangi penyerapan $\mathrm{CO}_{2}$ mengakibatkan kenaikan konsentrasi gas tersebut di atmosfir bumi [1].

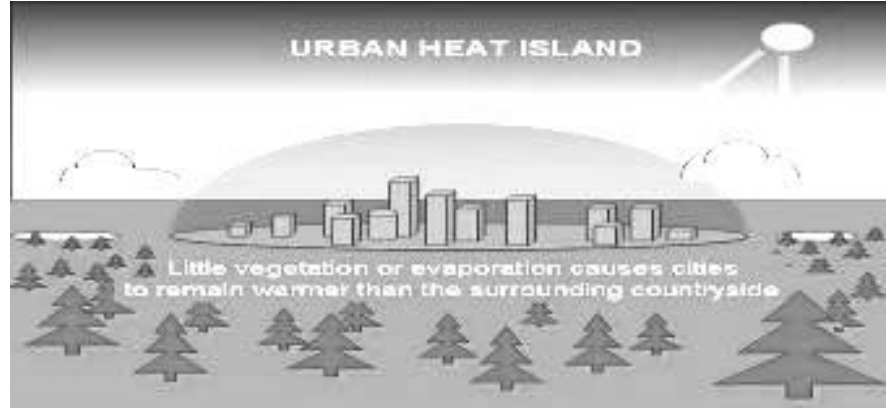

Gambar 1. Ilustrasi Urban Heat Island.

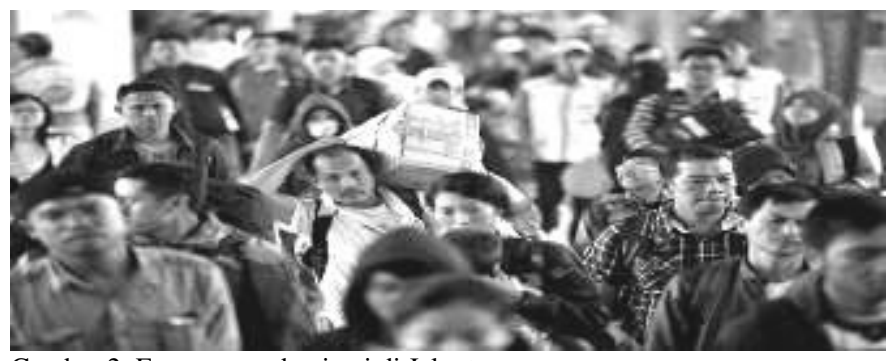

Gambar 2. Fenomena urbanisasi di Jakarta.

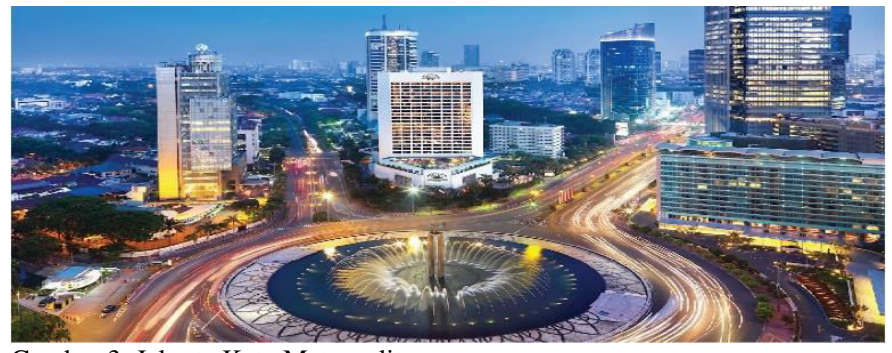

Gambar 3. Jakarta Kota Metropolitan.

Jika kita kerucut lagi masalah pemanasan global ini ke dalam konteks kota, kita akan menemukan fenomena urban heat island (UHI) yang sangat berpengaruh dalam menjadi penyebab terjadinya pemanasan bumi. UHI adalah fenomena dimana konsentrasi struktur dan limbah panas dari aktivitas manusia menghasilkan udara yang sedikit lebih hangat di daerah perkotaan jika dibandingkan dengan udara di sekitar daerah pedesaan.

Masalah urban heat island juga didukung dengan meningkatnya proses urbanisasi yang tak pernah berhenti. Urbanisasi menyebabkan banyak gedung dan bangunan baru yang diperlukan untuk mendukung berbagai aktifitas manusia. Selain itu, beberapa efek negatif urban heat island [2] diantaranya adalah pengurangan kualitas air dalam perkotaan 


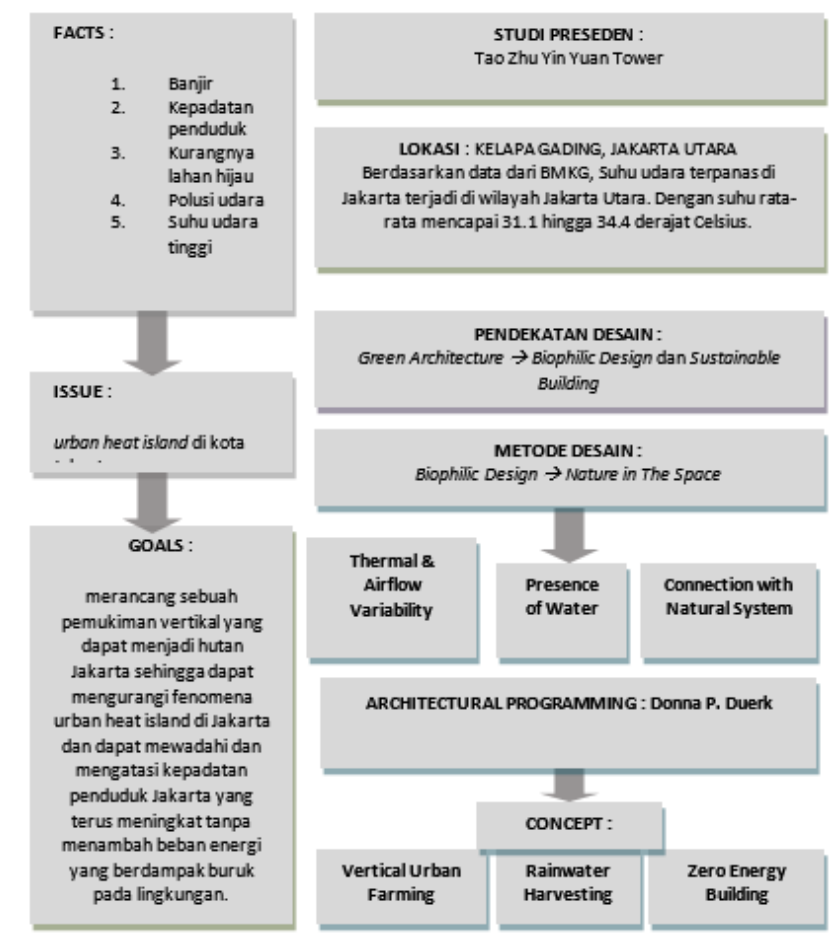

Gambar 5. Architectural Programming - Donna P. Dwerk.

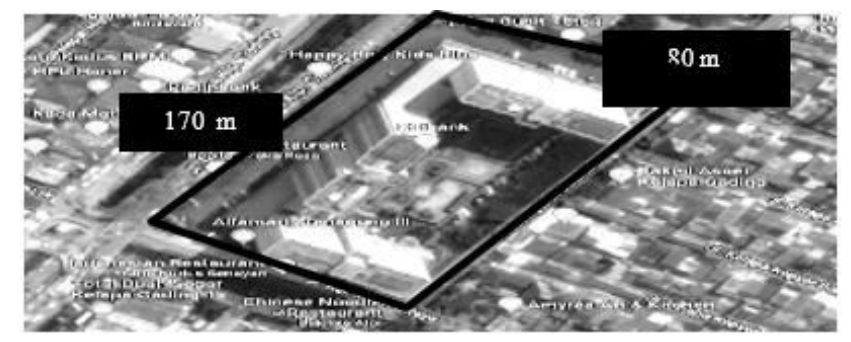

Gambar 6. Area Lahan pada rancangan.

akibat polusi dari panas berlebihan, peningkatan pemakaian listrik sebesar 5 - 6\% (Environmental Protection Agency, 2005) dan akibat dari pemakaian listrik yang meningkat, mendukung penambahan penggunaan bahan bakar fosil yang menyebabkan timbulnya pemanasan global.

Provinsi DKI Jakarta merupakan kota metropolitan terbesar di Asia Tenggara dan merupakan kota terbesar di Indonesia. Sehingga sampai saat ini, Jakarta sangat marak akan urbanisasi. Terutama pada kawasan Kelapa Gading, Jakarta Utara. Berdasarkan data dari Badan Meterologi, Klimatologi, dan Geofisika (BMKG), Suhu udara terpanas di Jakarta terjadi di wilayah Jakarta Pusat (Jakpus) dan Jakarta Utara (Jakut), dengan suhu rata-rata mencapai 31.1 hingga 34.4 derajat Celsius. Pada kawasan inilah dengan suhu udara dan kepadatan penduduk yang tinggi menyebabkan tingkat urban heat island semakin tinggi pula.

Sehingga, penulis merancang sebuah pemukiman vertikal dengan pendekatan biophilic design untuk mengurangi fenomena UHI di Jakarta. Karena, dengan permukiman vertikal akan dapat mengurangi atau meminimalisirkan luasan tapak yang dibutuhkan untuk menampung atau mewadahi kebutuhan penduduk yang cukup banyak, dan pendekatan

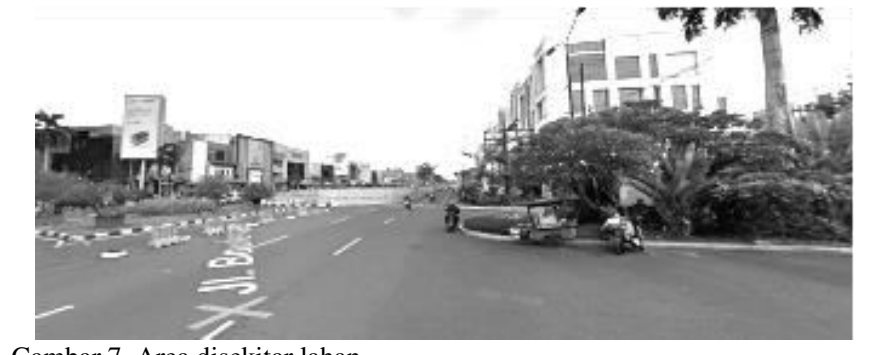

Gambar 7. Area disekitar lahan.

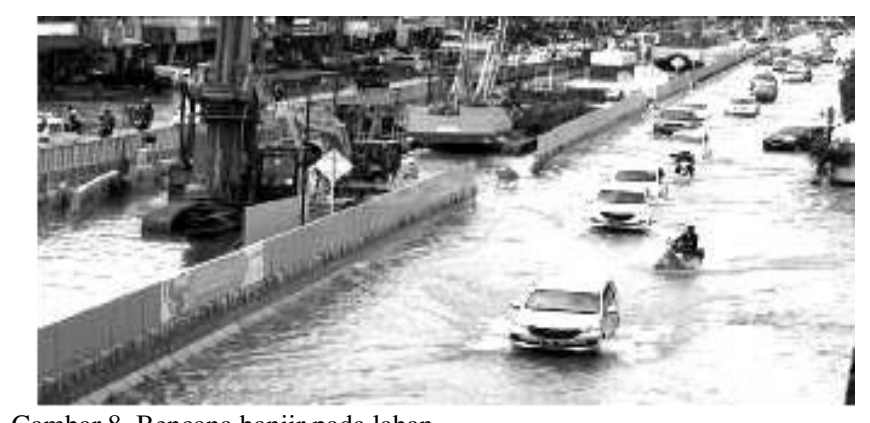

Gambar 8. Bencana banjir pada lahan.

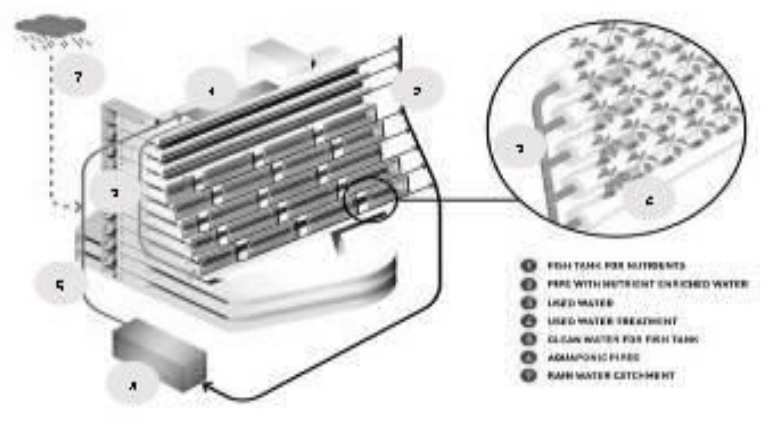

Gambar 9. Proses Rainwater harvesting.

biophilic dapat memenuhi kebutuhan tempat tinggal, sumber pangan dan air bersih penduduk.

\section{METODE DESAIN}

\section{A. Proses Desain}

Berdasarkan buku architectural programming [3], dijelaskan beberapa taapan dalam proses mendesain, diantaranya adalah sebagai berikut:

1. Fakta: Tahap menganalisis data-data dan permasalahan yang terjadi disekitar kita, baik dalam konteks kawasan, social, dsb.

2. Issue: dari fakta-fakta tersebut dirangkum dan didapati permasalahan utama dan terbesar.

3. Goals: menggambarkan objek rancang yang dapat mengatasi masalah isu diatas.

4. Studi Preseden: Menganalisis studi kasus yang sudah terbangun dan memiliki isu yang sama dengan rancangan

5. Selanjutnya tahap pemilihan lokasi rancang, pedekatan dan metode rancang, konsep rancang, dan hasil rancangan. 


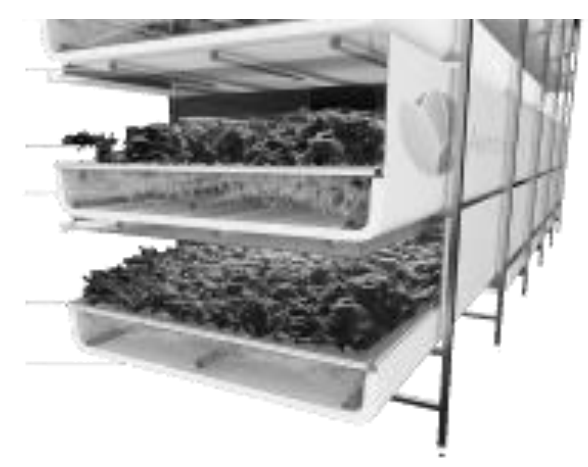

Gambar 10. Proses vertical harvesting.

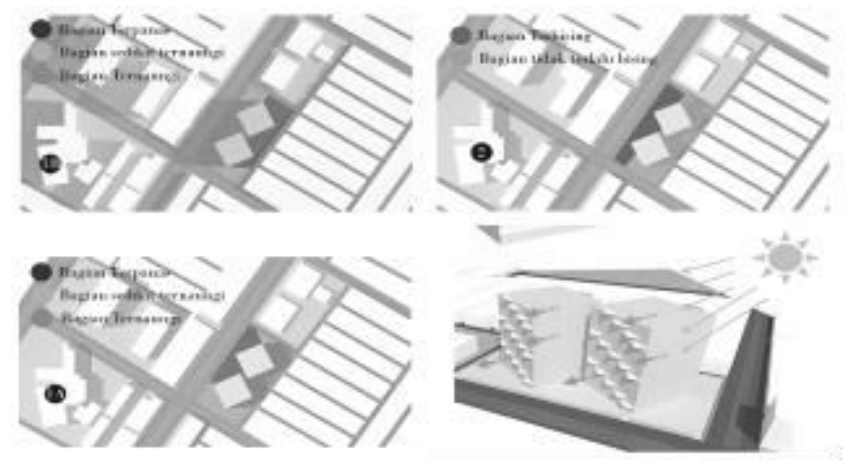

Gambar 11. Analisis Lahan dan orientasi bangunan.

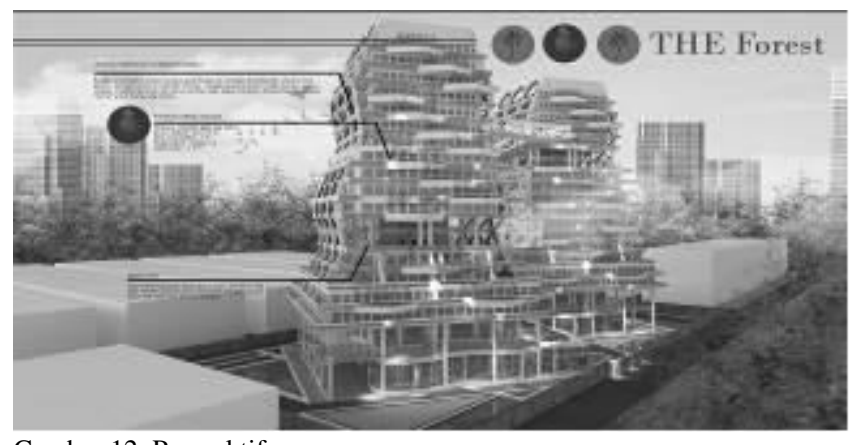

Gambar 12. Perspektif.

\section{B. Pendekatan Desain}

Dalam rancangan pemukiman vertikal, untuk menciptakan sebuah tempat tinggal yang dapat mengontrol iklim sekitar sehingga terciptanya kawasan yang sehat baik bagi manusia dan lingkungan, digunakan pendekatan biophilic design. Biophilic desain ini menciptakan habitat yang baik bagi manusia sebagai organisme biologis di bangunan dan konstruksi modern yang dapat meningkatkan kesehatan, kebugaran dan kesejahteraan manusia maupun lingkungan seiring dengan populasi dunia yang semakin meningkat. Secara sederhananya, desain biophilik adalah sebuah pendekatan desain yang mampu menyelaraskan kepentingan alam, manusia dan bangunan itu sendiri.

\section{Metode Desain}

Pada perkotaan urban heat island dominan disebabkan oleh kepadatan penduduk yang menyebabkan kurangnya lahan hijau yang dijadikan perumahan, perkantoran, dsb. Sehingga, metode desain yang digunakan adalah biophilic: nature in the space [4]. Metode ini merancang unsur alam (nature) kedalam

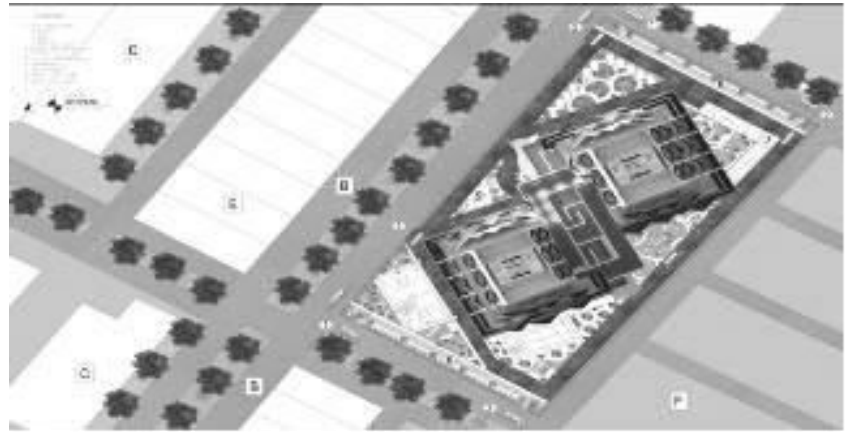

Gambar 13. Site plan.

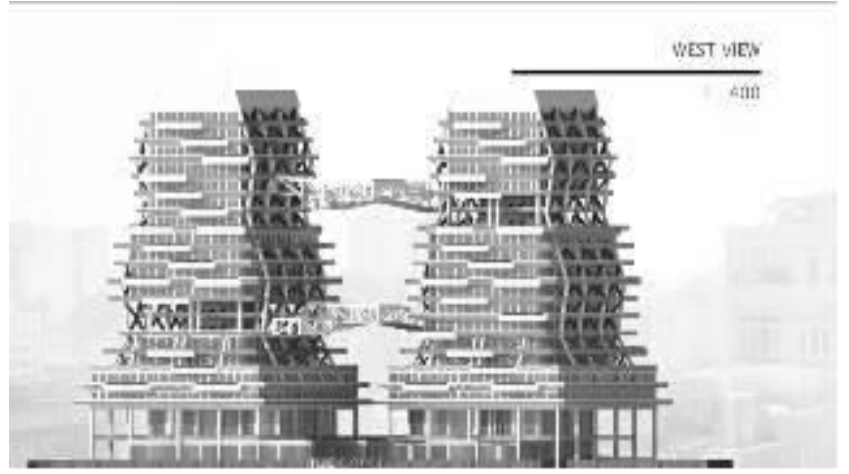

Gambar 14. Tampak Bangunan.

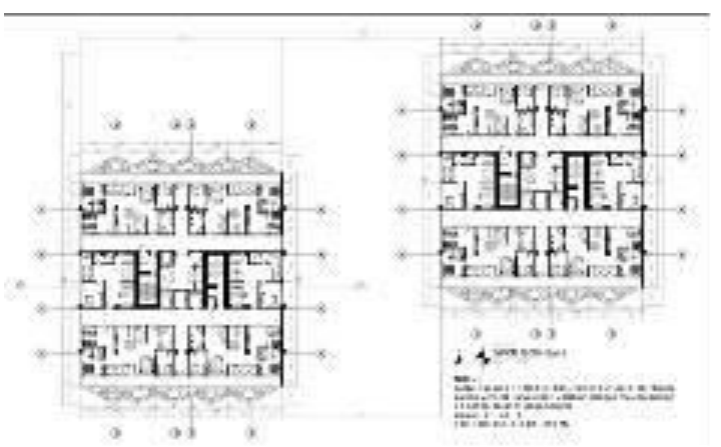

Gambar 15. Denah unit.

sebuah hunian vertikal (space) untuk mengembalikan lahan hijau yang sudah terpakai untuk kebutuhan konstruksi.

Pola yang digunakan dalam metode ini adalah:

1. Thermal \& Airflow Variability yaitu Pola yang mengatur termal (suhu) dan aliran udara pada bangunan/desain yang disesuaikan dengan lingkungan alami dan dapat memberikan perubahan positif bagi kesehatan manusia maupun lingkungannya.

2. Presence of Water yaitu pola yang menghadirkan unsur air. Selain dapat menenangkan dan menstimulasi manusia secara psikologis, unsur air juga berpengaruh pada kondisi termal pada bangunan maupun terhadap lingkungan sekitarnya. Pertimbangan desain pada pola ini adalah moving water.

\section{Konsep Desain Berdasarkan Metode Desain}

\section{Thermal \& Airflow Variability: Konsep Vertical Harvesting}

Istilah "vertical urban farming" dikemukakan oleh Gilbert Ellis Bailey pada tahun 1915 dalam bukunya Vertical 


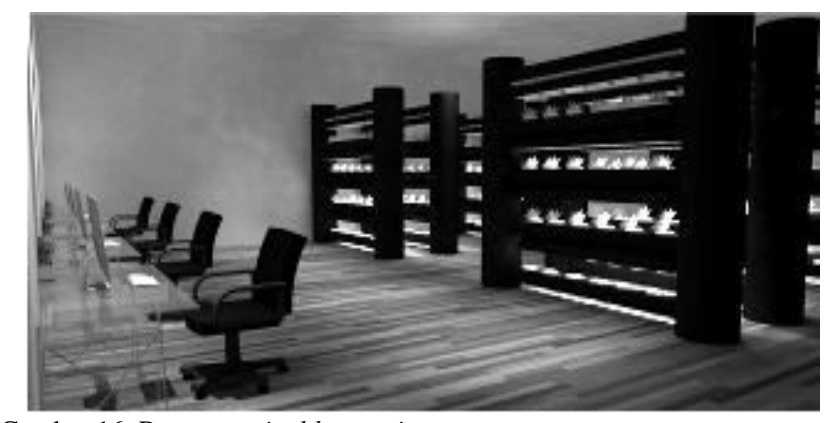

Gambar 16. Ruang vertical harvesting.

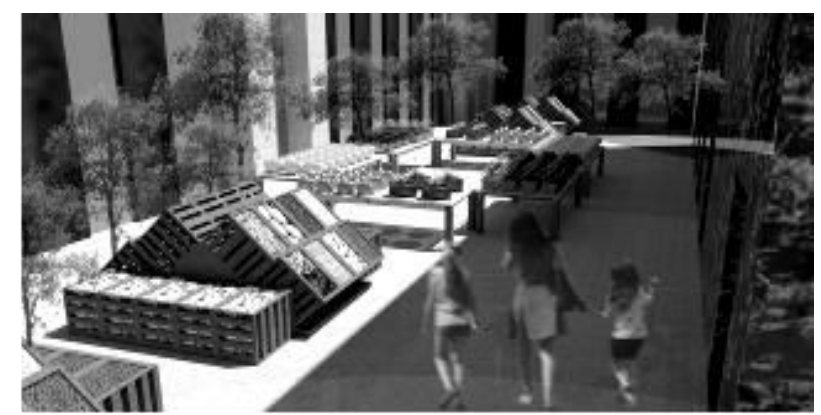

Gambar 17. Organic market.

Farming. Vertical Harvesting [5] itu sendiri adalah penanaman tumbuhan hijau dan sumber pangan (seperti pohon, sayuran dan buah-buahan) secara berlapis-lapis atau bertingkat. Perbedaan lainnya, farming disini tumbuh tanpa matahari atau tanah, dan berada didalam ruangan yang sepenuhnya terkontrol oleh para ahli.

Pada prosesnya, vertical harvesting menggunakan aeroponik untuk menghubungkan akar tumbuhan dengan nutrisi, air, dan oksigen. Sistem aeroponik itu sendiri adalah sistem loop tertutup, dan menggunakan air $95 \%$ lebih sedikit daripada pertanian lapangan. Kemudian, untuk memenuhi kebutuhan cahaya, digunakan lampu LED dengan spektrum cahaya yang spesifik pada setiap tanaman untuk membantu proses fotosintesis. Dengan cara tersebut, sangat membantu dalam hal hemat energi dan ramah ligkungan. Selain agar hemat energi, penggunaan LED ini memungkinkan kita untuk mengontrol ukuran, bentuk, tekstur, warna, rasa, nutrisi dan peningkatan produktivitas pada tumbuhan.

\section{Presence of Water: Konsep Rainwater Harvesting}

Rainwater harvesting adalah sistem yang dapat menampung dan menyaring air hujan berlebih, sehingga dapat menghasilkan air bersih yang dapat dialirkan keseluruh bangunan dan dapat digunakan kembali dalam kegiatan sehari-hari, seperti untuk mendinginkan bangunan \& suhu sekitar, untuk menyiram tanaman, flushing water, air minum, dan sebagainya [6]. Dengan memanfaatkan rainwater harvesting, dapat mengurangi penggunaan energi yang menyebabkan urban heat island dan dapat mengurangi biaya pemakaian energi (listrik).

Pada prosesnya, sebagian air hujan diserap oleh tanaman hijau yang terdapat pada atap, balkon ataupun lapangan terbuka pada sebuah bangunan. Kemudian air hujan tersebut menyerap kedalam tanah dan disaring oleh batuan antrasit, kerikil, tanah garnet dan pasir. Kemudian air tanah tersebut disaring kembali dengan teknologi filter air. Setelah disaring,

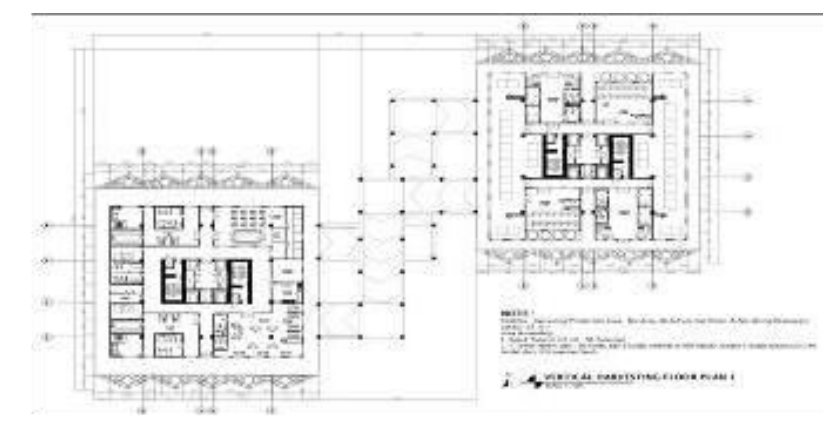

Gambar 18. Denah vertical harvesting.

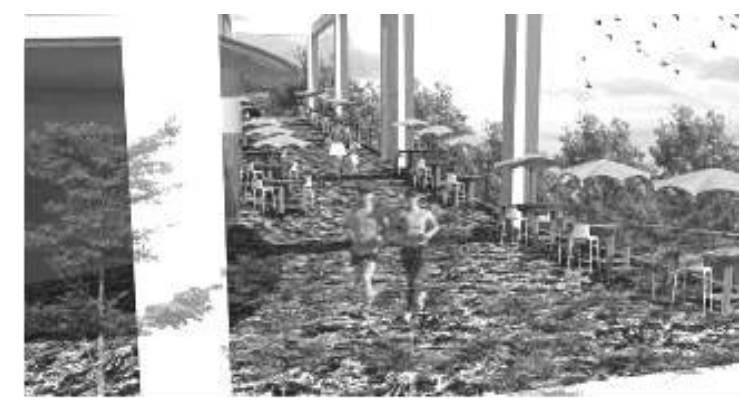

Gambar 19. Area fasilitas.

air bersih tersebut dipompa keseluruh bangunan (untuk keperluan penghuni), ke dinding bangunan, sebagai sumber air bagi vertical harvesting dan sisanya di tampung di tandon.

\section{HASIL PERANCANGAN}

A. Mission

Misi utama dalam perancangan apartemen ini adalah untuk memperbaiki iklim serta mengurangi fenomena urban heat island di Jakarta. Selain itu juga dapat mengatasi masalah kepadatan penduduk Jakarta yang terus meningkat tanpa menambah beban energi yang berdampak buruk pada lingkungan.

\section{B. Konsep Desain Utama}

Konsep utama dari rancangan apartemen ini yaitu menjadi hutan bagi kota Jakarta. Sebagaimana kita ketahui, hutan adalah sumber penghidupan bagi makhluk hidup. Berikut adalah beberapa manfaat konsep hutan:

1. Dapat mengurangi urban heat island (UHI) dengan menyaring polusi (panas maupun udara) di perkotaan.

2. Dapat memberikan udara besih dan menjadi paru-paru kota (sumber oksigen)

3. Dapat menjadi sumber air bersih alami.

4. Dapat menghasilkan sumber pangan (sayur dan buahbuahan) bagi manusia.

5. Sebagai tempat bernaung \& berlindung demi kenyamanan fisik maupun psikologis manusia.

\section{Konsep Ide Bentuk}

Dikarenakan konsep utama rancangan ini adalah hutan, terciptalah bentuk bangunan terinspirasi dari sebuah gunung. Sebuah gunung yang besar, menjulang dan dikelilingi pepohonan hijau yang rindang begitulah bayangan dari ide bentuk pada rancangan ini. Proses pembentukan bentuk 


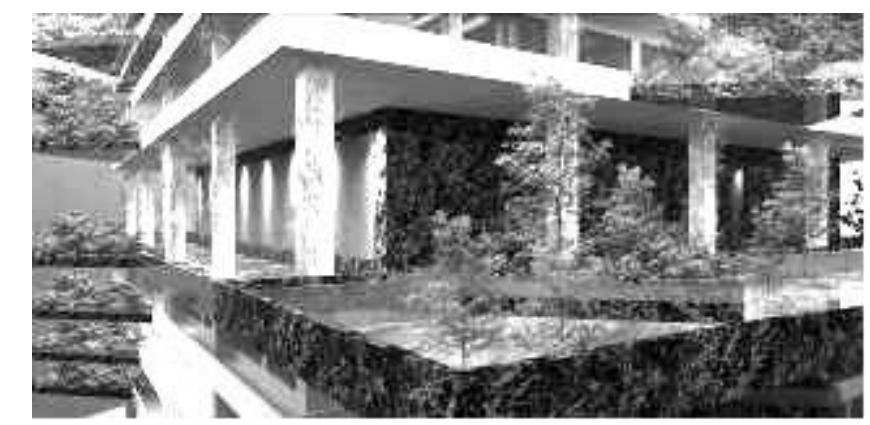

Gambar 20. Green dan water wall.

rancangan berdasar pada bentuk geometri sederhana yaitu sebuah kubus pipih. Bentuk tersebut di maju-mundurkan (sistem set-back) secara acak untuk menciptakan bentuk seperti bukit-bukit atau jalan menuju puncak gunung. Selain itu, bagian tengah dicuak/dilubangi untuk berperan sebagai kawah gunung. Kawah gunung ini bertujuan untuk meresap dan menyimpan air hujan untuk keperluan harian pengguna.

\section{Konsep Orientasi Bangunan}

Berdasarkan orientasi matahari didapati data sebagai berikut:

1. 7-9 AM: level dari UV-A terendah pada saat ini (good for human health)

2. 10 AM-3PM: level dari UV-A tertinggi pada saat ini dan pada saat ini juga UV-B rays mulai dihasilkan ( good for plant growth)

3. 4-6 PM: Baik untuk kesehatan psikologi manusia. Untuk menikmati ketenangan dari kesejukan dan momen matahari tenggelam.

Sehingga, orientasi bangunan mengikuti sumber matahari dan bising terbanyak berdasarkan analisis lahan. Pada pagi hari, orientasi bangunan difokuskan pada arah timur dan tenggara. Sedangkan untuk sore hari, orientasi bangunan difokuskan pada arah barat, barat daya dan barat laut.

\section{E. Konsep Vertical Harvesting}

Jakarta utara menghasilkan $\mathrm{CO}_{2}$ sebesar 5 juta ton pertahunnya. Agar dapat menyeimbanginya, bangunan rancang harus dapat menghasilkan $\mathrm{O}_{2}$ sebesar $\mathrm{CO}_{2}$ yang ada dikawasan tersebut. Sehingga, konsep yang diusulkan yaitu penanaman pohon (vertical farming) dengan jumlah $\pm 900-1000$ pohon dalam 1 tower bangunan. Karena, berdasarkan studi preseden, 1 ton $\mathrm{CO}_{2}$ dapat diserap sekitar \pm 175 pohon [7].

Selain untuk menyerap $\mathrm{CO}_{2}$ di udara, vertical harvesting ini juga dapat memenuhi kebutuhan pangan penduduk. Berdasarkan penelitian WHO, dianjurkan mengkonsumsi sayuran dan buah-buahan untuk hidup sehat sejumlah 5 tanaman per-orang perharinya. Maka kebutuhan sayuran/buah yang harus dihasilkan oleh bangunan sebesar 160.000 gram/hari nya atau sekitar \pm 2000 tanaman.

\section{F. Konsep Rainwater Harvesting}

Bangunan harus dapat mengurangi beban air hujan yang akan diserap tanah perkotaan (mengurangi banjir) dan bangunan dapat memanfaatkan air hujan untuk $\pm 75 \%$ dari berbagai keperluan users sehari-hari. Keperluan manusia akan air bersih perharinya sebesar 150-180 L. sehingga, kebutuhan untuk \pm 300 penghuni sebesar \pm 50.000 L. Manfaat dari rainwater harvesting selain sebagai sumber air bersih, juga dapat berfungsi sebagai nutrisi untuk buah dan sayuran hasil produksi vertical harvesting. Proses sistem rainwater harvesting ini adalah sebagai berikut:

1. Air hujan diserap oleh balkon bangunan kemudian dialirkan ke seluruh bangunan untuk keperluan harian pengguna.

2. Beberapa air dari balkon di alirkan ke fish tank sehingga air memiliki tambahan nutrisi. Kemudian, air tersebut dialirkan dengan pipa menuju pipa aeroponic sebagai nutrisi vertical harvesting.

3. Air kotor yang telah terpakai dialirkan menuju penampungan air bawah tanah dan disaring, sehingga air dapat digunakan kembali.

\section{KESIMPULAN}

Apartemen ini dirancang dengan menggunakan pendekatan biophilic dengan harapan terciptanya kelarasan antara manusia, alam dan bangunan yang ditempati. Pada desain ini lebih banyak memanfaatkan unsur alam seperti matahari, tumbuhan/pohon dan air hujan. Rancangan apartemen ini menanamkan $\pm 900-1000$ tumbuhan dan pepohonan yang disebarkan pada setiap sisi bangunan dan fasad untuk mengurangi polusi udara, suara dan menjadikannya sebagai "hutan kota". Kemudian, apartemen ini menerapkan sistem rainwater harvesting yang memanfaatkan air hujan berlebih yang dapat memenuhi kebutuhan sumber air bersih penghuni sebesar $\pm 50 \%$.

Selain itu, apartemen ini juga menerapkan sistem vertical harvesting yang dapat menyediakan sumber pangan bagi pengguna maupun penduduk sekitar kawasan tersebut.

Adapun jenis pangan yang ditanam adalah sebagai berikut, selada, bayam, tanaman herbal, strawberry, tomat cherry, dan kacang-kacangan. Ke-6 jenis tanaman tersebut dipilih karena memiliki perakaran yang pendek dan kompak, tidak tumbuh terlalu panjang atau tinggi, dan tidak terlalu berat [8]. Dengan begitu, apartemen ini dapat menjawab kebutuhan untuk mengurangi isu urban heat island pada kawasan tersebut.

\section{DAFTAR PUSTAKA}

[1] T. H. Karyono, "Konsekuensi Perubahan Iklim Dan Lingkungan Terhadap Strategi Perancangan Kota Di Indonesia," Bandung, 2006.

[2] A. V. Limas, A. Perdana, Nandhika, and H. Tannady, "Pembahasan Mengenai Efek Urban Heat Island dan Solusi Alternatif Bagi Kota Jakarta." Jakarta, 20014.

[3] D. P. Duerk, "Architectural Programing." 1993.

[4] W. D. Browning, C. O. Ryan, and J. O. Clancy, 14 Patterns Of Biophilic Design: Improving Health \& Well-Being In The Built Environment. New York: Terrapin Bright Green, LLC, 2014.

[5] Anonymous, "Aerofarms Technology," 2018.

[6] Sarma, "Rooftop Rainwater Harvesting System." [Online]. Available: http://www.iitg.ac.in/bpccp/BORUN/RWH.pdf.

[7] P. Lynch, "Vincent Callebaut Architectures' Double Helix EcoTower Takes Shape in Taiwan," 2016. .

[8] Anonymous, "Jenis Tanaman Pangan Terbaik Untuk Vertical Garden," 2016. 